Journal of Physical Science, Vol. 29(Supp. 2), 1-13, 2018

\title{
Thermal Characteristics of Microwave Reactor for Pyrolysis of Food Waste
}

\author{
Samsudin Anis, ${ }^{*}$ Yanuar Adi Kurniawan, Wirawan Sumbodo, Rais Alhakim and \\ Suprayoga Edi Lestari \\ Department of Mechanical Engineering, Universitas Negeri Semarang, Kampus Sekaran, \\ Gunungpati, Semarang, 50229 Indonesia \\ *Corresponding author: samsudin_anis@mail.unnes.ac.id
}

Published online: 30 July 2018

To cite this article: Anis, S. et al. (2018). Thermal characteristics of microwave reactor for pyrolysis of food waste. J. Phys. Sci., 29(Supp. 2), 1-13, https://doi.org/10.21315/ jps2018.29.s2.1

To link to this article: https://doi.org/10.21315/jps2018.29.s2.1

\begin{abstract}
Food waste generated from restaurants or food stalls needs to be processed correctly to minimise environmental pollution problems. One of the promising methods is pyrolysis process using low-power microwave energy reactor that can convert it into bio-oil. This process is strongly associated with the thermal heating process in a microwave reactor normally indicated by the reaction temperature, heating rate and the thermal efficiency. This work studies the thermal characteristics of microwave reactor during pyrolysis of food waste. A modified domestic microwave oven with a maximum output power of $418 \mathrm{~W}$ was used as the experimental reactor in this study. The samples with different moisture content (MC) of $11 \%$ and $24 \%$ were examined under various microwave power of $257 \mathrm{~W}, 362 \mathrm{~W}$ and $418 \mathrm{~W}$ for $1 \mathrm{~h}$. The results showed that the thermal characteristics of microwave were influenced by the microwave powers and moisture contents of the food waste. High microwave power and low MC provide high reaction temperature, heating rate and thermal efficiency. Under investigated conditions, the optimum result was obtained at microwave power of $418 \mathrm{~W}$ and $\mathrm{MC}$ of $11 \%$ in which final temperature, heating rate and thermal efficiency of the pyrolysis process were $757^{\circ} \mathrm{C}, 12.1^{\circ} \mathrm{C} \mathrm{min}-1$ and $53 \%$, respectively. These results indicated that the modified microwave reactor is capable for pyrolysis of food waste even at relatively low microwave power.
\end{abstract}

Keywords: Thermal characteristic, microwave reactor, pyrolysis, food waste, moisture content 


\section{INTRODUCTION}

Billions of tons of waste, particularly municipal solid waste (MSW) are generated annually worldwide. The waste amount constantly increases in line with the high population growth and needs. Hoornweg and Bhada-Tata reported that about 1.3 billion tons MSW is produced every year and it is expected to rise to 2.2 billion tons by $2025 .{ }^{1}$ Report by the Indonesia's Ministry of Environment shows that the amount of waste increased from around 64 million tons in 2015 to 65 million tons in Indonesia in 2016. Of these, $48 \%$ of the waste was generated from households. In addition, based on its composition, organic waste occupies $60 \%$ of the waste generated. Among the MSW, food waste is one of the prominent wastes generated from canteens, restaurants, kitchens of residential societies, food industries, etc. ${ }^{2}$ Today, disposal of large amount of food waste has become a challenge. There is an urgent need for proper management, reuse or processing of food waste.

Chemically, food waste contains hydrocarbon materials such as lipids, carbohydrates, amino acids and other substances. Because of its high carbohydrate and lipid content, food waste contains more hydrogen and its $\mathrm{H} / \mathrm{C}$ ratio is much higher than that of other biomasses. ${ }^{3}$ These materials can be converted into other forms of energy including gaseous, biodiesel, bioethanol, bio-oil, etc. ${ }^{4-7}$ Pyrolysis has been known as one of the effective methods for biomass processing. In this method, the biomass is thermally processed in the absence of air to produce products such as char, oil, combustible gases and valuable chemicals. ${ }^{8}$ So far, conventional heating sources such as electric and gas heater is the most used system by the researchers for biomass pyrolysis. Apart from the successful application of conventional heating, several recent literature works show that research activities on biomass pyrolysis in developing alternative energy resources under microwave heating have gained more attention. Biomass pyrolysis heated by microwave irradiation could be a more promising technique due to the unique feature of volumetric heating of materials. This feature could result in a more rapid heating process leading to significant energy and process time saving, yield improvement, fewer hazardous compounds generation and higher heating efficiency.9,10

Studies on MSW and food waste pyrolysis using microwave reactor have been reported. ${ }^{8,11}$ In general, the main used parameters for assessing the yield of products obtained from microwave processing of waste include microwave power, addition of absorber and catalyst, as well as moisture content of the material. It should be noted that to obtain better result, the microwaves should be able to enter the materials and generate heat. On this basis, the processed material that exhibits good dielectric properties can be used directly as it can absorb microwave energy and then convert it into heat. Nevertheless, materials have different responses to 
microwave heating which indicate that the dielectric properties of the materials vary widely. ${ }^{12}$

Although research on the processing of food waste using microwave heating has been done as described, the research mainly focuses on the production of liquid or gaseous fuels. In fact, there are many other important parameters that need to be investigated in detail in order to improve the performance of a microwave reactor. One of the crucial parameters is thermal characteristics of microwave reactor associated with the materials to be processed. Therefore, in this work, thermal characteristics of microwave reactor for pyrolysis of food waste in terms of temperature evolution, heating rate and thermal efficiency are investigated. With the aim to obtain optimal conditions and achievable technical performance, several parameters including microwave power, irradiation time and moisture content (MC) of food waste were studied.

\section{EXPERIMENTAL}

\subsection{Materials}

The food waste used in this study consisted of a mixture of rice, vegetables and meats which was obtained from some bins of nearby restaurant. It was then separated into two parts. The first part was used as received while the other part was dried in the sun for a day before use. With these treatments, both samples had MC of $24 \%$ and $11 \%$, respectively.

\subsection{Experimental Apparatus}

Figure 1 shows the schematic diagram of the experimental apparatus. It mainly consists of a microwave reactor and a cooling system as previously reported. ${ }^{13} \mathrm{~A}$ refractory reactor with a size of $84 \mathrm{~mm}$ inner diameter and $125 \mathrm{~mm}$ length was installed vertically in the microwave chamber and designed as a fixed bed reactor. The reactor had a thermocouple positioned at the centre of the reactor and contained food waste to be processed. Commercial microwave oven with a frequency of $2.45 \mathrm{GHz}$ was modified to allow pyrolysis processes. The microwave oven has an input and a maximum output power of $450 \mathrm{~W}$ and $700 \mathrm{~W}$, respectively. To monitor the temperature of the microwave cavity, a thermocouple was also applied. In order to avoid damage of the microwave unit, the temperature of microwave cavity should be kept below $200^{\circ} \mathrm{C}$. In this work, temperatures of the reactor and microwave cavity were measured using a $3 \mathrm{~mm}$ outer diameter K-type stainless steel sheathed thermocouple that satisfies measurement of temperature in electromagnetic field. 
Grounding of the metallic sheath to the chamber is required to avoid arcing. The cooling system consisted of a double pipe condenser and a liquid collector of $250 \mathrm{ml}$ glass bottle. Teflon and copper pipes with a size of $9.5 \mathrm{~mm}$ inner diameter were used for transporting volatile substance from refractory reactor to liquid collector generated during pyrolysis process.

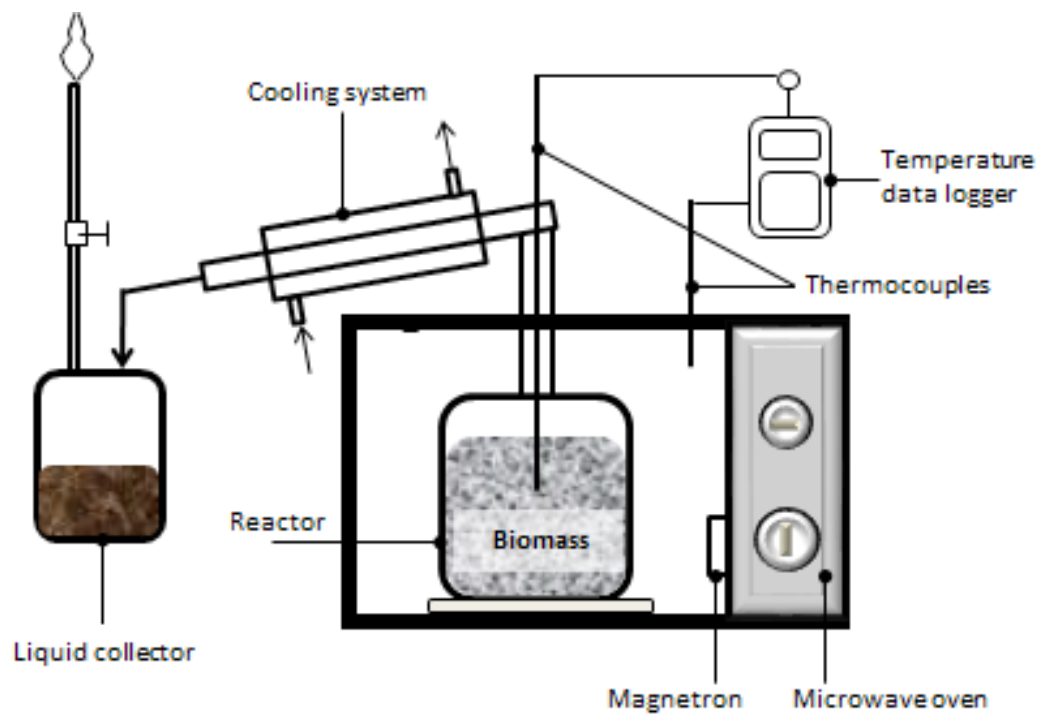

Figure 1: Schematic diagram of the experimental apparatus.

\subsection{Thermal Heating Experiment}

Various parameters including microwave power and moisture content of food waste were employed to study thermal characteristic of microwave reactor in terms of temperature evolution, heating rate and thermal efficiency. There were three levels of microwave power, i.e., medium $(257 \mathrm{~W})$, medium-high $(362 \mathrm{~W})$ and high power $(418 \mathrm{~W})$, and two levels of moisture content (11\% and $24 \%)$ applied in the experiments. In each experimental test, the amount of food waste treated within the reactor was kept constant at $300 \mathrm{~g}$ and tested for $60 \mathrm{~min}$ of irradiation time. During the experiment, temperatures of the reactor and microwave cavity were recorded every $30 \mathrm{~s}$. After the designated irradiation time, the microwave oven was automatically switched off. Then, the system was allowed to cool to ambient temperature. This procedure was repeated for each set of conditions investigated.

In this work, thermal efficiency $\left(\eta_{T}\right)$ and absorbed microwave power $\left(P_{\text {abs }}\right)$ were calculated based on the equations in the following. ${ }^{13}$ 


$$
\begin{aligned}
& \eta_{\mathrm{T}}=\frac{\mathrm{P}_{\mathrm{abs}}}{\mathrm{P}_{\mathrm{MW}}} \times 100 \% \\
& \mathrm{P}_{\mathrm{abs}}=\left[\mathrm{mc}_{\mathrm{p}}\left(\frac{\mathrm{T}_{2}-\mathrm{T}_{1}}{\mathrm{t}}\right)\right]+\left[\mathrm{hA}\left(\mathrm{T}_{2}-\mathrm{T}_{1}\right)\right]+\left[\varepsilon \sigma \mathrm{A} \overline{\mathrm{T}}^{4}\right]
\end{aligned}
$$

where $\mathrm{P}_{\mathrm{Mw}}$ is the chosen microwave power (W), $\mathrm{m}$ is the mass of material $(\mathrm{kg})$, $\mathrm{C}_{\mathrm{p}}$ is the heat capacity of material $\left(\mathrm{J} \mathrm{kg}^{-1} \mathrm{~K}^{-1}\right), \mathrm{T}_{1}$ and $\mathrm{T}_{2}$ are the initial and final temperatures $(\mathrm{K})$ respectively, $\mathrm{t}$ is the irradiation time $(\mathrm{s}), \mathrm{h}$ is the convective heat transfer coefficient $\left(\mathrm{W} \mathrm{m}^{-2} \mathrm{~K}^{-1}\right), \mathrm{A}$ is the area of the object $\left(\mathrm{m}^{2}\right), \varepsilon$ is the emissivity of material, $\sigma$ is the Stefan-Boltzmann constant $\left(5.67 \times 10^{-8} \mathrm{~W} \mathrm{~m}^{-2}\right.$ $\mathrm{K}^{-4}$ ), and $\overline{\mathrm{T}}$ is the average temperature within the microwave reactor $(\mathrm{K})$.

\section{RESULTS AND DISCUSSION}

\subsection{Effect of Microwave Power}

In order to evaluate the effect of microwave power on the thermal characteristics of microwave reactor consisting of temperature profile, heating rate and thermal efficiency, a series of studies were performed. Figure 2 shows temperature profile of microwave reactor at three different microwave powers during thermal decomposition of food waste with MC of $24 \%$. As indicated in the figure, the reactor temperature is highly influenced by the microwave power. It increases with the increase of microwave power. The highest temperature was obtained at $418 \mathrm{~W}$, which was the highest microwave power applied in this study. After $1 \mathrm{~h}$ of irradiation time, reactor temperature of $265^{\circ} \mathrm{C}, 442^{\circ} \mathrm{C}$ and $552^{\circ} \mathrm{C}$ could be reached using microwave power of $257 \mathrm{~W}, 362 \mathrm{~W}$ and $418 \mathrm{~W}$, respectively. These results showed that the absorbed microwave power by the material inside reactor increased as the incident microwave power increased, therefore the temperature within the reactor would also increase. The results were in line with previous works which reported that the absorbed microwave power is highly influenced by the electric field. ${ }^{13-15}$ It should be noted that at maximum microwave power, the material in the reactor was exposed continuously by the high intensity of microwave energy (continuous mode), while at lower microwave power, the material was only exposed periodically by microwave energy (pulse mode). 


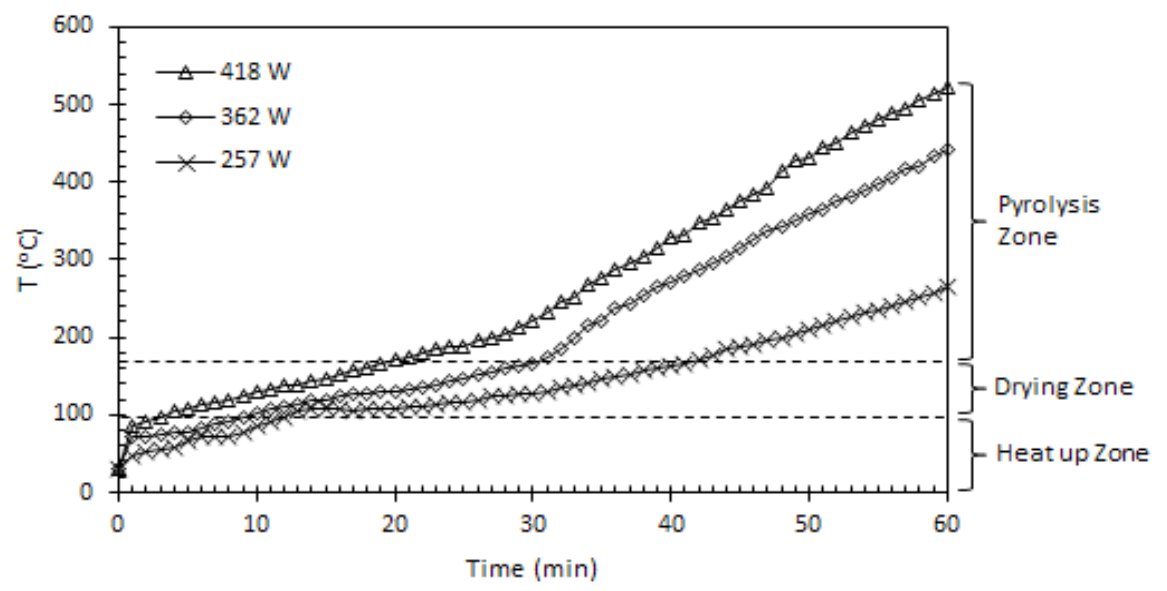

Figure 2: Temperature profile of microwave reactor at various microwave powers for food waste with $24 \% \mathrm{MC}$ during 60 min of irradiation time.

Figure 2 also shows three heating zones during thermal process of food waste indicated by the reactor temperatures evolution. The first is heat-up zone where the reactor temperatures increased rapidly up to around $100^{\circ} \mathrm{C}$ particularly for microwave power of $362 \mathrm{~W}$ and $418 \mathrm{~W}$. The high MC of food waste that absorbs microwave energy well is considered as the main factor affecting reactor temperatures. The second is drying zone where reactor temperatures increased slowly up to about $170^{\circ} \mathrm{C}$ due to evaporation of water within the samples. The last is pyrolysis zone in which volatile materials were released. In this zone, thermal decomposition of organic materials into other products including carbon-rich solid products (bio-char), condensable (liquid) products and non-condensable (gaseous) products are formed. In this zone, the high increase of temperature during thermal process could be due to the formation of bio-char that absorbs microwave energy and converts it into heat. The literature showed that bio-char is one of good absorber materials in microwave processing. ${ }^{16}$

Figure 3 shows the heating rate of microwave reactor for food waste with MC of $24 \%$ at various microwave powers. It was evaluated every $5 \mathrm{~min}$ of irradiation time. In general, heating rate reduced gradually up to a specific irradiation time for all microwave power applied. After that time, heating rate increased slightly for microwave power of $362 \mathrm{~W}$ and $418 \mathrm{~W}$ whereas for lower microwave power of $257 \mathrm{~W}$, heating rate seemed to be constant. It can be observed that the highest heating rates were reached in the first $5 \mathrm{~min}$ of irradiation, i.e., $7^{\circ} \mathrm{C} \mathrm{min}^{-1}, 9.4^{\circ} \mathrm{C}$ $\mathrm{min}^{-1}$ and $15.8^{\circ} \mathrm{C} \mathrm{min}^{-1}$ for $257 \mathrm{~W}, 362 \mathrm{~W}$ and $418 \mathrm{~W}$, respectively. At irradiation

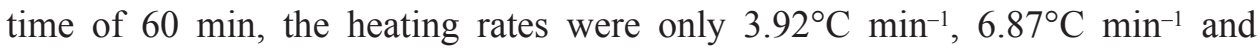


$8.2^{\circ} \mathrm{C} \mathrm{min}^{-1}$, respectively. Similar observation was also reported in other studies. ${ }^{13-15}$ The reduction of heating rate is due to the penetration depth of microwave power changes during processing. It will decrease when the material temperature rises. This change was strongly associated with relative values of dielectric constant and loss factor of material. These variables are primarily dependent on the temperature.

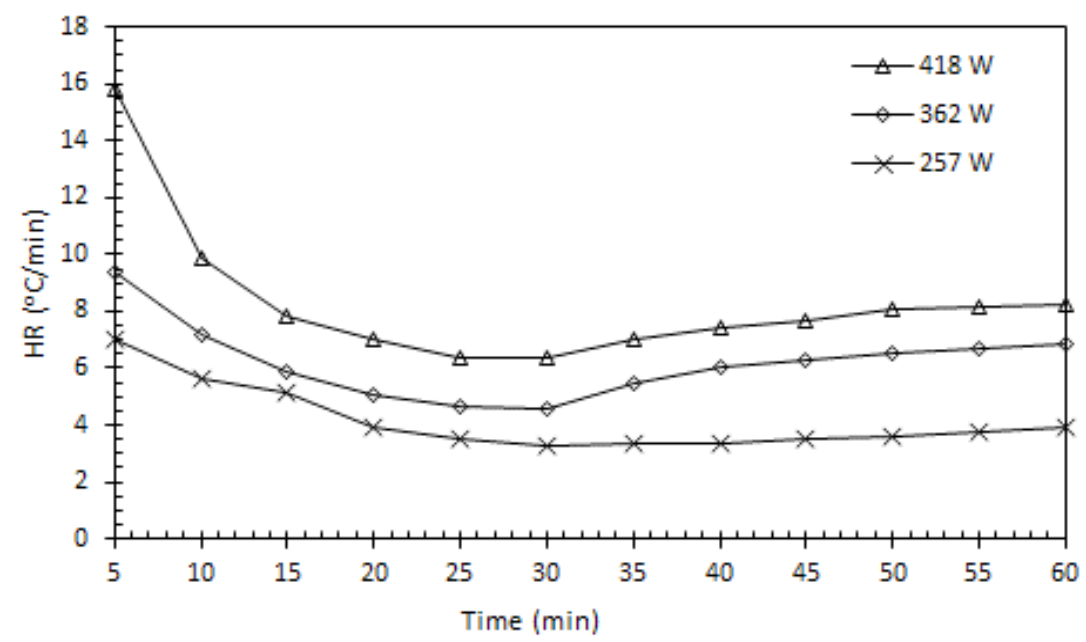

Figure 3: Heating rate of microwave reactor for food waste with $24 \% \mathrm{MC}$ at various microwave powers.

Figure 4 shows thermal efficiency of microwave reactor at various microwave powers during thermal decomposition of food waste with $\mathrm{MC}$ of $24 \%$. It was also evaluated every $5 \mathrm{~min}$ of irradiation time. As in the case of heating rate, below 30 min of irradiation, thermal efficiency generally decreased significantly for all microwave power applied, then increased due to the formation of carbon-rich solid products. High microwave powers provided better thermal efficiency. It can be observed from the figure that in the first $5 \mathrm{~min}$ of irradiation, thermal efficiencies were $30.82 \%, 29.07 \%$ and $41.79 \%$ for $257 \mathrm{~W}, 362 \mathrm{~W}$ and $418 \mathrm{~W}$, respectively. While, at irradiation time of $30 \mathrm{~min}$, thermal efficiencies were only $16.37 \%, 16 \%$ and $19.21 \%$, respectively, showing the reduction of thermal efficiencies of about $49 \%$ on average. This condition occurred due to drying process of food waste where the absorbed microwave energy is mainly utilised for water evaporation rather than for heating process. ${ }^{17}$ 


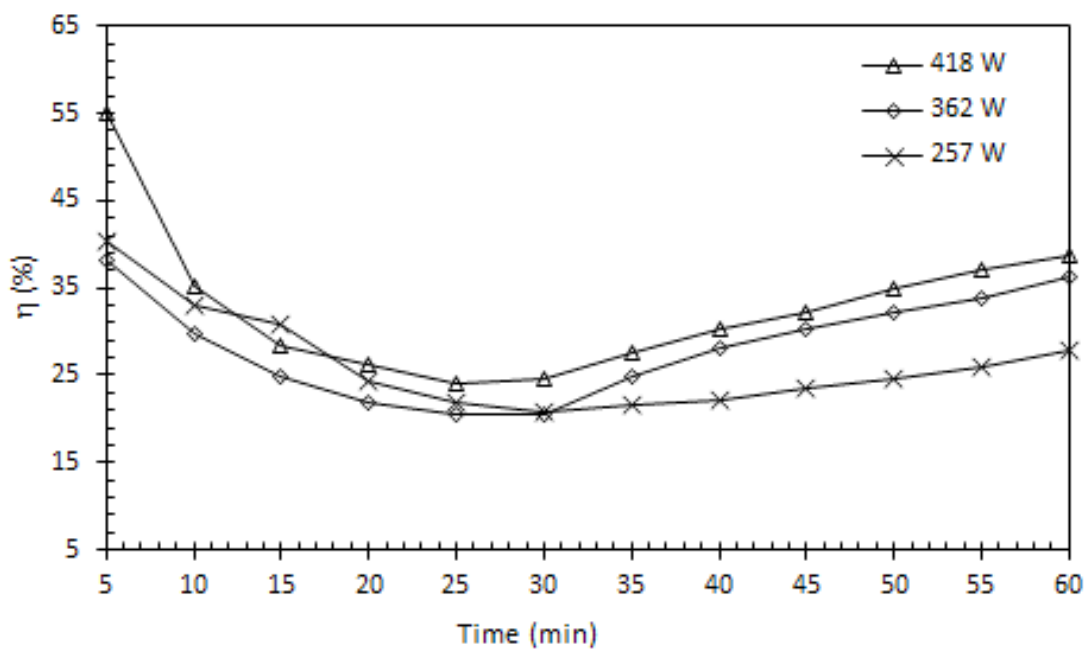

Figure 4: Thermal efficiency of microwave reactor for food waste with $24 \% \mathrm{MC}$ at various microwave powers.

\subsection{Effect of MC}

Effect of food waste $\mathrm{MC}$ on the reactor temperature, heating rate and thermal efficiency was tested at a fixed microwave power of $418 \mathrm{~W}$ for $60 \mathrm{~min}$ of irradiation. Figure 5 shows temperature evolution as a function of irradiation time at MC of $11 \%$ and $24 \%$. The figure indicates that moisture content significantly affects reactor temperature. After $60 \mathrm{~min}$ of irradiation, reactor temperature reached $757^{\circ} \mathrm{C}$ and $522^{\circ} \mathrm{C}$ for $\mathrm{MC}$ of $11 \%$ and $24 \%$, respectively. This result suggested that lower $\mathrm{MC}$ of food waste provided rapid increase of reactor temperature during thermal process. It could be observed from the figure that reactor temperature of about $170^{\circ} \mathrm{C}$ could be reached in short irradiation time of 1 min only for MC of $11 \%$. In contrast, for $\mathrm{MC}$ of $24 \%$, longer irradiation time of about 20 min was needed that could be attributed to water evaporation. The low water content is preferable in microwave heating of material. ${ }^{17}$ Nevertheless, beyond $170^{\circ} \mathrm{C}$, the increase in reactor temperature was relatively similar for both $11 \%$ and $24 \%$ although the obtained maximum temperatures are different. This condition showed that formation of carbon-rich solid products played a major role in microwave thermal heating process. This result is in line with previous studies that the absorbed microwave power increased with the increase of amount of absorber material due to formation of carbon-rich solid products. ${ }^{16,18}$ 


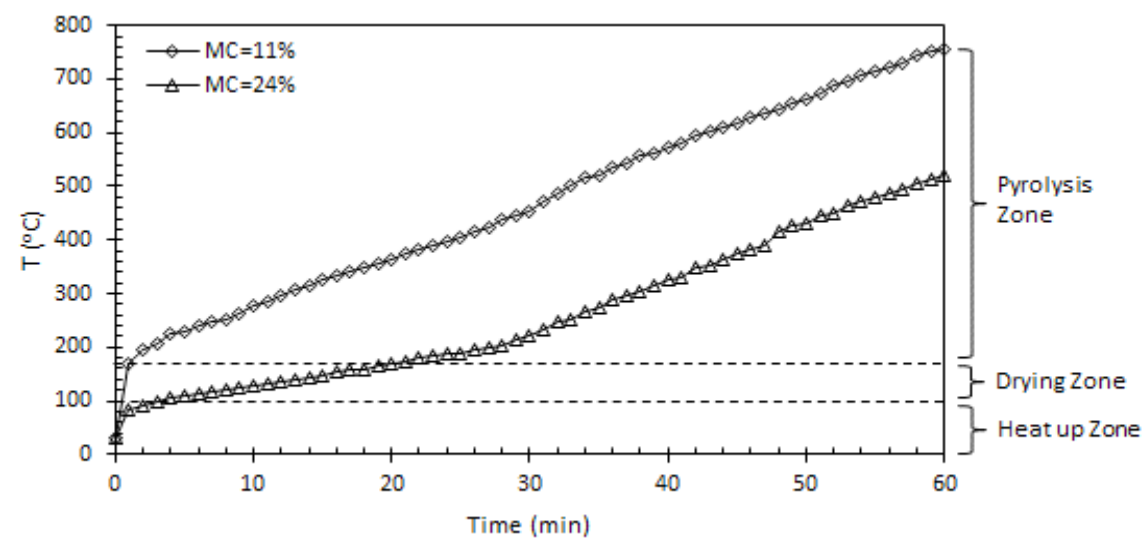

Figure 5: Temperature profile as a function of irradiation time at various MC.

Studies on the effect of food waste MC on the reactor temperature also show three heating zones including heat up, drying and pyrolysis zones as shown in Figure 5. Nevertheless, special interest for lower MC of $11 \%$ due to rapid increase of temperature during heating process, only two heating zones could be observed, i.e., heat up/drying zone and pyrolysis zone. This result showed that material with low MC allows quick evaporation of water that contributes to reduction of energy consumption for heating processes.

The heating rate for two different food waste MC is presented in Figure 6. In general, heating rate decreased up to a certain irradiation time before becoming constant. The decrease of heating rate corresponds to reduction of water content contained in the sample during the process. It can be observed from the figure that heating rates of the microwave reactor with $\mathrm{MC}$ of $11 \%$ was much higher than that of the system with $\mathrm{MC}$ of $24 \%$. It can be evaluated that during 60 min of irradiation, the average heating rates were around $12.12^{\circ} \mathrm{C} \mathrm{min}-1$ and $8.2^{\circ} \mathrm{C} \mathrm{min}^{-1}$ for food waste MC of $11 \%$ and $24 \%$, respectively. The high heating rates of the system with low $\mathrm{MC}$ not only provide high reactor temperature but also reduce the required heating time as depicted earlier in Figure 5. For example, reactor temperature of $250^{\circ} \mathrm{C}$ could be attained in 8 min with food waste $\mathrm{MC}$ of $11 \%$ whereas it needed about $33 \mathrm{~min}$ for $\mathrm{MC}$ of $24 \%$. 


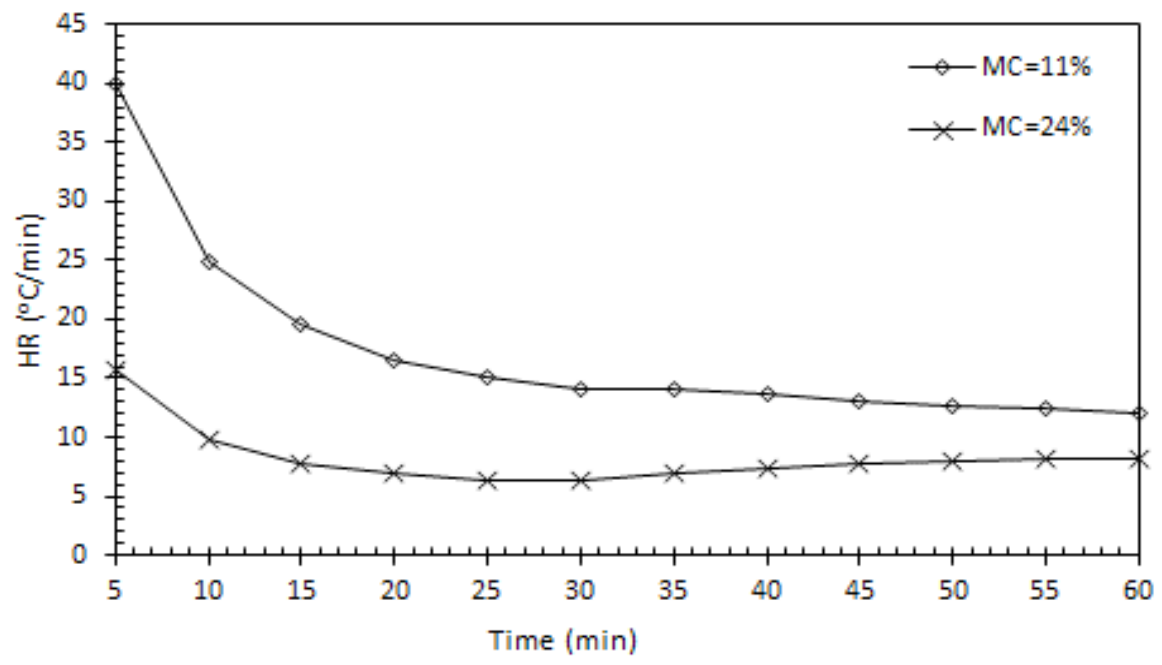

Figure 6: Heating rate at various food waste MC.

Thermal efficiency as a function of irradiation time for food waste MC of $11 \%$ and $24 \%$ can be observed in Figure 7. In general, thermal efficiency decreased significantly during $25 \mathrm{~min}$ of irradiation before linearly increased. In this condition, the calculation results showed that the thermal efficiency of the system with MC of $11 \%$ decreased from $84.23 \%$ after $5 \mathrm{~min}$ to about $46.86 \%$ at final irradiation time studied. While for food waste MC of $24 \%$, it was $41.79 \%$ to $31.51 \%$, respectively. These results showed that in the range of irradiation time investigated, the food waste with low MC have higher thermal efficiency of microwave reactor compared to the other. It should be noted that the thermal efficiency of microwave reactor is influenced by various factors such as initial and final temperatures, irradiation time, heat capacity, etc., as given in Equations 1 and 2. In this case, the first two parameters are considered the main factors contributing to the high thermal efficiency of the sample with MC of $11 \%$. 


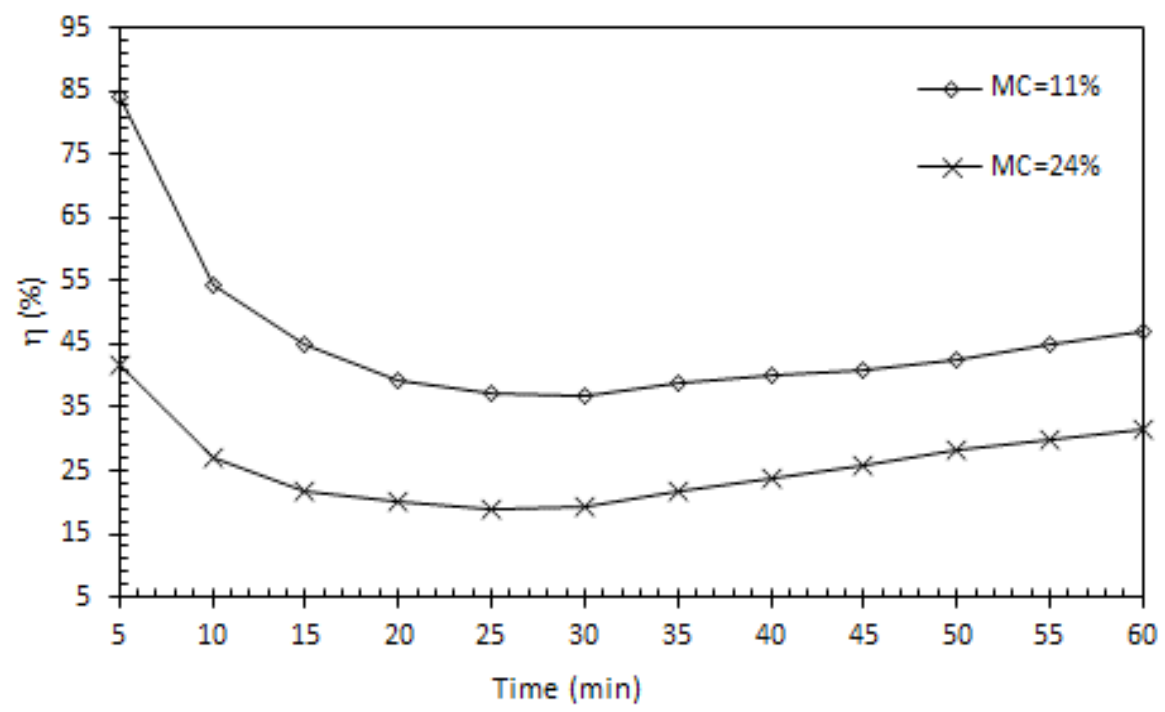

Figure 7: Thermal efficiency at various food waste MC.

\section{CONCLUSION}

Thermal characteristics of microwave reactor for pyrolysis of food waste has been investigated. The results showed that the microwave power and moisture content of food waste were found to be the main factors affecting reactor temperature, heating rate and thermal efficiency. System with higher microwave power and lower MC were preferred for processing of food waste under microwave irradiation. Microwave power of $418 \mathrm{~W}$ and $\mathrm{MC}$ of $11 \%$ provided higher temperature, heating rate and thermal efficiency. As a whole, pyrolysis of food waste by using microwave reactor is highly potential to produce alternative fuel for power generation and transportation.

\section{ACKNOWLEDGEMENTS}

The authors gratefully acknowledge the research grant 1.1.7/PPK.4.5/2016 awarded by the Faculty of Engineering, Universitas Negeri Semarang, Indonesia to carry out this work. 


\section{REFERENCES}

1. Hoornweg, D. \& Bhada-Tata, P. (2015). What a waste: A global review of solid waste management. Washington: World Bank.

2. Barik, S. \& Paul, K. K. (2017). Potential reuse of kitchen food waste. J. Environ. Chem. Eng., 5(1), 196-204, https://doi.org/10.1016/j. jece.2016.11.026.

3. Sun, Z. et al. (2014). Mixed food waste as renewable feedstock in succinic acid fermentation. Appl. Biochem. Biotechnol., 174(5), 1822-1833, https:// doi.org/10.1007/s12010-014-1169-7.

4. Karmee, S. K. \& Lin, C. S. K. (2014). Valorisation of food waste to biofuel: Current trends and technological challenges. Sustain. Chem. Process., 2(1), 22, https://doi.org/10.1186/s40508-014-0022-1.

5. Pham, T. P. T. et al. (2015). Food waste-to-energy conversion technologies: Current status and future directions. Waste Manage., 38, 399-408, https:// dx.doi.org/10.1016/j.wasman.2014.12.004.

6. Yang, X. et al. (2014). Production of bioethanol and biodiesel using instant noodle waste. Bioproc. Biosys. Eng., 37(8), 1627-1635, https://doi. org/10.1007/s00449-014-1135-3.

7. Lin, C. S. K. et al. (2014). Current and future trends in food waste valorization for the production of chemicals, materials and fuels: A global perspective. Biofuels Bioprod. Bioref., 8, https://doi.org/10.1002/bbb.1506.

8. Beneroso, D. et al. (2014). Influence of the microwave absorbent and moisture content on the microwave pyrolysis of an organic municipal solid waste. J. Anal. Appl. Pyrol., 105, 234-240.

9. Yin, C. (2012). Microwave-assisted pyrolysis of biomass for liquid biofuels production. Bioresour. Technol., 120, 273-284, https://doi.org/10.1016/j. biortech.2012.06.016.

10. Anis, S. \& Zainal, Z. A. (2013). Upgrading producer gas quality from rubber wood gasification in a radio frequency tar thermocatalytic treatment reactor. Bioresour. Technol., 150, 328-337, https://doi.org/10.1016/j. biortech.2013.10.010.

11. Liu, H. et al. (2014). The catalytic pyrolysis of food waste by microwave heating. Bioresour. Technol., 166, 45-50, https://doi.org/10.1016/j. biortech.2014.05.020.

12. Appleton, T. J. et al. (2005). Microwave technology for energy-efficient processing of waste. Appl. Energy, 81(1), 85-113, https://doi.org/10.1016/j. apenergy.2004.07.002. 
13. Anis, S. et al. (2017). Thermal characteristics analysis of microwaves reactor for pyrolysis of used cooking oil. Paper presented at the AIP Conference Proceedings, 5th International Conference on Education, Concept, and Application of Green Technology, Semarang, 3-5 October, 020003, https:// doi.org/10.1063/1.4976867.

14. Anis, S., Zainal, Z. A. \& Bakar, M. Z. A. (2013). Thermocatalytic treatment of biomass tar model compounds via radio frequency. Bioresour. Technol., 136, 117-125, https://doi.org/10.1016/j.biortech.2013.02.049.

15. Huang, Y. F. et al. (2010). Hydrogen-rich fuel gas from rice straw via microwave-induced pyrolysis. Bioresour. Technol., 101(6), 1968-1973, https://doi.org/10.1016/j.biortech.2009.09.073.

16. Menéndez, J. A. et al. (2010). Microwave heating processes involving carbon materials. Fuel Process. Technol., 91(1), 1-8, https://doi.org/10.1016/j. fuproc.2009.08.021.

17. Omar, R. et al. (2011). Characterization of empty fruit bunch for microwaveassisted pyrolysis. Fuel, 90(4), 1536-1544, https://doi.org/10.1016/j. fuel.2011.01.023.

18. Salema, A. A. \& Ani, F. N. (2011). Microwave induced pyrolysis of oil palm biomass. Bioresour. Technol., 102(3), 3388-3395, https://doi.org/10.1016/j. biortech.2010.09.115. 